\title{
Prevalence and Ergonomic Risk Factors of Work-related Musculoskeletal Injuries amongst Underground Mine Workers in Zambia
}

\author{
Richard Kunda, Josè Frantz and Farhana KaRACHI \\ Physiotherapy Department, University of the Western Cape, South Africa
}

\begin{abstract}
Prevalence and Ergonomic Risk Factors of Work-related Musculoskeletal Injuries amongst Underground Mine Workers in Zambia: Richard Kunda, et al. Physiotherapy Department, University of the Western Cape, South Africa-Work-related musculoskeletal injuries (WMSIs) are common in both developed and third world countries. Most researchers agree that exposure to ergonomic risk factors is a major contributor to these injuries. Objective: The aim of this study was to determine the prevalence of and ergonomic risk factors associated with WMSIs amongst underground mine workers in Kitwe, Zambia. Methods: A cross-sectional quantitative study was conducted using a sample size of 500 workers. A stratified random sampling method according to mining work activity type was used to obtain the sample. Data was collected by means of a structured questionnaire, and the Statistical Package for Social Sciences (SPSS) was used to analyze data using descriptive and inferential statistical methods. Results were significant at $5 \%$. Results: A response rate of $40.4 \%$ (202) was obtained. The 12month prevalence of WMSIs was $42.6 \%$. The mean age of the workers was 40.31 years (SD +/- 8.57 years). Electricians and mechanics reported the highest injury frequencies. The back was the most affected body part. Ergonomic risk factors consistently reported by workers included poor postures and heavy lifting. There were significant $(p=0.020)$ associations between working with the back bent and sustaining a back injury. Significant $(p=0.049)$ associations were also found between injuries of the wrists/hands and grasping an unsupported object(s). Conclusions: This study revealed significant associations between WMSIs and ergonomic risk factors like working with the back bent and grasping
\end{abstract}

Received Aug 19, 2011; Accepted Mar 14, 2013

Published online in J-STAGE Apr 13, 2013

Correspondence to: $R$. Kunda, University of the Western Cape, Physiotherapy Department, South Africa

(e-mail:princerk1@gmail.com)

All authors have contributed to the design, draft and final submission of the article. $R$ Kunda was the main researcher and data collector. objects.

(J Occup Health 2013; 55: 211-217)

Key words: Ergonomics, Mine workers, Musculoskeletal injury, Prevalence, Risk Factors

Mining has been characterized by most researchers as one of the most hazardous occupations amongst major industrial activities ${ }^{1-3)}$. Despite regulations, automation and increased attention towards reducing risks through safety campaigns, the mining industry is still associated with higher rates of injuries compared with other industries ${ }^{4-6)}$. Mine workers must deal with a number of subtly harmful risks to safety and health, such as a high concentration of mechanical equipment in a confined space. As a result, mine workers are often exposed to a high risk of WMSIs ${ }^{7,8)}$. Occupational risk in underground mining is much higher than in surface mining ${ }^{6,9}$. Underground mining involves drilling, charging and blasting to access and recover ore ${ }^{1)}$ and mine workers are required to perform labor-intensive tasks that can often not be avoided due to limited work space ${ }^{3)}$.

Since the establishment of Zambia as a nation, copper has been the single largest contributor to the Zambian economy ${ }^{10)}$. At independence in 1964, copper accounted for $91 \%$ of the total export earnings ${ }^{11}$. This commodity still remains critically important for the Zambian economy ${ }^{12)}$. An area of great concern in considering increased copper production and utilization is the health and safety of workers who mine or process the product. According to the Zambia Congress of Trade unions (ZCTU), most employers in Zambia do not pay attention to the health and safety of their employees, as they consider this to be costly ${ }^{13)}$. The excesses in WMSIs associated with copper mining in Zambia, indicate the need for more comprehensive surveillance of copper mines. Given the rising number of work-related accidents, there is an urgent need for the development and 
implementation of appropriate measures for preventing WMSIs amongst mine workers ${ }^{6}$, particularly as the reliance upon copper increases.

To date, no studies have reported on the prevalence of and ergonomic risk factors associated with WMSIs amongst mine workers in Zambia. Therefore, a description and understanding of the effects of exposure profiles in underground mines based on the results of epidemiological investigations is required ${ }^{14)}$. The purpose of the current study was to determine the prevalence of and ergonomic risk factors associated with WMSIs amongst underground mine workers in Zambia.

\section{Materials and Methods}

\section{Study subjects}

The study was conducted on underground mine workers from four underground shafts at Mopani mines in Kitwe, Zambia. The total number of workers was 1,896 . The data was retrospectively collected over a period of one year. A cross-sectional quantitative study design was used. To ensure proportional representation of the population, a stratified random sampling technique according to job types was used to realize the sample of this study. In the first stage, mine workers were grouped into seven (7) strata according to job types, namely, mechanics, electricians, diesel loader drivers, miners, supervisory, locomotive drivers and others. The others category constituted "minor" occupations with few workers like callout clerks, Bobcat drivers, draughtsman, pump chamber operators and surge bin operators. The sample was then drawn proportionally within each stratum using random number tables. An estimated sample size of 500 mine workers was computed with the margin of error of 0.05 using the approach outlined by Bartlett, Kotrlik and Higgins ${ }^{15)}$. If a selected mine worker decided not to participate in the study or was reported absent, we passed on to the next candidate until we had the required number of participants in each stratum. This technique ensured an optimal chance of drawing a sample that would be representative of the population from which it was drawn.

The participants were given instructions by the researcher and research assistants on how to complete the questionnaires.

\section{Questionnaire}

Various questionnaires were used to compile the questionnaire for this study, namely, the Standardized Nordic questionnaire ${ }^{16)}$, Modified version of the Washington state risk factor checklist $^{6)}$ and the upper limb Core QX checklist ${ }^{17}$. These questionnaires were used in guiding the design. The questionnaire was divided into three sections. In the first section, the mine workers were required to provide demographic and other general information. The second part of the questionnaire consisted of an injury profile. This section recorded data on whether the worker had had an injury while on duty during the preceding 12 months. A "yes" response was used to ascertain the prevalence of work-related musculoskeletal injuries. Mine workers were also required to indicate the anatomical location (body parts) of the injury sustained, and more than one response was permitted. The third section of the questionnaire constituted questions on ergonomic risk factors. This section measured the characteristics of the work environment and work practices like machines used, postures adopted at work and total work duration per day.

The questionnaire was designed in English because the English language was the minimum qualification for employment at the mine.

In order to provide estimates of exposures to ergonomic risk factors for underground mine workers, miners participating in this study were asked to report risk factor exposures for their specific job. For many of the risk factors, two conditions were presented, which were the indicators for caution (a lower level of risk) and hazard (a higher level of risk). The operational definitions for the ergonomic risk factors considered in this study are listed in Table 1 below.

Prior to obtaining an overview of the actual situation in which the investigation was conducted, content validation of the questionnaire was done by senior lecturers at the School of Mines and Department of Physiotherapy of the University of Zambia. A pilot study was then undertaken to assess whether the participants easily understood questions asked and how long it would take to complete the questionnaire. This provided feedback regarding the clarity of the questions and the overall presentation of the questionnaire. In order to avoid biased responses, the subjects of the pilot study were automatically excluded from the main study.

The internal consistency of the overall instrument used in this study was assessed with the Cronbach's alpha. The reliability analysis indicated a high estimate of internal consistency (Cronbach's alpha $=0.53-0.9$ ). According to conventional rules, any coefficient exceeding 0.70 is regarded as high ${ }^{18)}$. Regarding face validity, the participants found the questions short and understandable and the whole form required approximately 20 minutes to complete. The team of lecturers (experts) at the University of Zambia found the content of the questionnaire valid and representative of work-related problems faced by mine workers.

Five hundred (500) questionnaires were distributed to participants in the four mine shafts. One hundred 
Table 1. Operational definitions for ergonomic hazards

Heavy lifting (HL): Lifting unaided an object heavier than $25 \mathrm{~kg}(55 \mathrm{lbs})$ more than 10 times per day

Awkward postures (AP): Lifting an object above head level, working with the neck bent more than 30 degrees without support, working with a bent wrist, working with the back bent without support, squatting and kneeling for two or more hours.

High hand force (HF): Pinching an unsupported object, grasping unsupported objects, grasping plus wrists bent for two or more hours.

Highly repetitive work (RW): Work involving repeating the same motion with little or no variation every few seconds for two or more hours.

Vibration tools (VT): Work involving use of vibrating tools such as grinders, jig saws or other hand tools that typically have moderate vibration levels for two or more hours.

Bouncing or jarring (BJ): Work involving operating mobile equipment for two or more hours.

Static postures (SP): Sitting or standing in a restricted space for two or more hours without changing positions.

Pushing and pulling (PP): Work involving pushing or pulling against an object, like a trolley, with a maximum effort eight or more times per day.

Table 3 adapted from Winn, Biersner and Morrissey (1996).

and twenty-five (125) questionnaires were distributed in each shaft. If any participant presented with injury, measures were put in place to ensure appropriate referral to the health practitioners at the mine hospital. Participants were allowed to complete the questionnaires at their own convenience due to the nature of their jobs, as the majority of them worked in shifts. Completed questionnaires where then collected with the aid of shift supervisors.

\section{Data analysis}

The data were captured and analyzed using SPSS version 15.0. Descriptive statistics of the data, namely frequencies expressed as percentages, were used to obtain information on the prevalence of WMSIs, body parts injured and number of workers exposed to ergonomic hazards. Inferential statistical analysis was used to determine the associations between ergonomic risk factors and injury. This was done in the form of cross-tabulations. Associations between variables were evaluated by means of the chi-square test. The alpha level was set at 0.05 . Data were summarized in terms of percentages and frequencies.

Ethical clearances for the study were secured from the Study Grant Ethics Committee of the University of the Western Cape, Mopani Copper Mines (MCM) management and the Ministry of Mines and Minerals Development (MMMD). Written feedback was obtained from both the MCM management and the MMMD. In addition, written consent was sought from all participants.

\section{Results}

Sample response rate

A total of 500 questionnaires were provided to mine workers, out of which 202 were completed. This yielded a $40.4 \%$ response rate. Two hundred and ninety-eight (298) were misplaced or not returned. All the participants in this study were male workers, since there were no female underground mine workers.

\section{Demographic characteristics of participants}

The mine workers who participated in the study were between 23 and 60 years old (mean $=40.31$; $\mathrm{SD}=8.572$ years). The experience of the mine workers ranged from 1 to 35 years (mean=13.92 years; and $\mathrm{SD}=9.743$ years). Many mine workers had less than 5 years of work experience $(n=82,40.2 \%)$.

\section{Injury prevalence}

Eighty-six (42.6\%) miners had sustained at least one injury from mining activities during the preceding year. Table 2 below summarizes the injury frequencies in various mine occupations. Among the occupations, those presenting with the highest number of injuries were electricians, who reported 16 (53\%) injuries, followed by mechanics, who reported 19 $(50 \%)$ injuries, while the least number of injuries was noticed among diesel loader drivers, who reported 8 $(33 \%)$ injuries; no injuries were reported among locomotive drivers.

The most affected body parts among the mine workers were the wrist/hand, lower back and neck. Electricians sustained the highest number of neck, upper back and shoulder injuries. The supervisory category constituting mine captains, section bosses, senior engineers and senior surveyors reported the shoulders and wrists/hands as the most affected body regions. Overall, mechanics reported the highest 
number of neck and shoulder injuries, while miners had the most frequently reported hand/wrist injuries among all underground mine occupations. The highest number of upper back injuries was observed among electricians, while injuries of the lower back were frequently reported by miners. Loader drivers reported the highest number of ankle/feet injuries.

Table 2. Injury prevalence by mine occupation $(n=86)$

\begin{tabular}{lccc}
\hline Occupation & $\begin{array}{l}\text { Number } \\
\text { of workers }\end{array}$ & $\begin{array}{l}\text { Injury } \\
\text { frequency }\end{array}$ & $\begin{array}{l}\text { Percentage } \\
(\%)\end{array}$ \\
\hline Electricians & 30 & 16 & 53 \\
Mechanics & 38 & 19 & 50 \\
Diesel loader drivers & 24 & 8 & 33 \\
Miners & 33 & 13 & 39 \\
Locomotive drivers & 5 & 0 & 0 \\
Supervisors & 41 & 19 & 46 \\
Others & 31 & 11 & 35 \\
\hline
\end{tabular}

Forty-eight workers from various mining job categories reported multiple bodily injuries. There was no significant association between body part injured and occupation. Table 3 below shows the body part injury distribution among various underground mining occupations.

\section{Ergonomic risk factors}

To provide estimates of exposure with regard to common ergonomic risk factors, mine workers were asked to report their exposure to risk factors for their job.

The respondents reported 691 ergonomic risk factors among the 7 mining occupations surveyed. Using worker task and facility characteristics, as well as the exposure durations, estimates were made of population exposures to eight (8) ergonomic risk factors for each mining occupation. The most common risk factors reported were heavy lifting (123 exposures), followed by awkward postures (100 exposures) and repetitive

Table 3. Percentage of body part injury per occupation $(n=86)$

\begin{tabular}{|c|c|c|c|c|c|c|c|}
\hline \multicolumn{8}{|l|}{ Title of occupation } \\
\hline $\begin{array}{l}\text { Affected } \\
\text { body part }\end{array}$ & Electrician & Mechanic & Loader driver & Miner & Loco. driver & Supervisors & Others \\
\hline Neck & $6(20 \%)$ & $8(21 \%)$ & $3(13 \%)$ & $7(21 \%)$ & $0(0 \%)$ & $5(13 \%)$ & $4(13 \%)$ \\
\hline Shoulder & $6(20 \%)$ & $8(21 \%)$ & $1(4 \%)$ & $3(9 \%)$ & $0(0 \%)$ & $8(20 \%)$ & $3(10 \%)$ \\
\hline Elbow & $2(7 \%)$ & $0(0 \%)$ & $1(4 \%)$ & $2(6 \%)$ & $0(0 \%)$ & $2(5 \%)$ & $2(7 \%)$ \\
\hline Wrists/hands & $5(17 \%)$ & $8(21 \%)$ & $1(4 \%)$ & $8(24 \%)$ & $0(0 \%)$ & $8(20 \%)$ & $5(16 \%)$ \\
\hline Upper back & $6(20 \%)$ & $4(11 \%)$ & $2(8 \%)$ & $1(3 \%)$ & $0(0 \%)$ & $3(7 \%)$ & $4(13 \%)$ \\
\hline Lower back & $5(17 \%)$ & $7(18 \%)$ & $4(17 \%)$ & $8(24 \%)$ & $0(0 \%)$ & $9(22 \%)$ & $5(16 \%)$ \\
\hline Hips/thighs & $2(7 \%)$ & $3(7 \%)$ & $3(13 \%)$ & $3(9 \%)$ & $0(0 \%)$ & $2(5 \%)$ & $3(10 \%)$ \\
\hline Knees & $3(10 \%)$ & $4(10 \%)$ & $3(13 \%)$ & $4(12 \%)$ & $0(0 \%)$ & $3(7 \%)$ & $1(3 \%)$ \\
\hline Ankles/feet & $3(10 \%)$ & $4(11 \%)$ & $5(21 \%)$ & $3(9 \%)$ & $0(0 \%)$ & $3(7 \%)$ & $4(13 \%)$ \\
\hline Multiple injuries & $7(23 \%)$ & $17(45 \%)$ & $5(21 \%)$ & $13(39 \%)$ & $0(0 \%)$ & $6(14 \%)$ & $0(0 \%)$ \\
\hline
\end{tabular}

Table 4. Percentage of workforce in each occupation exposed to ergonomic risk factors

\begin{tabular}{lcccccccc}
\hline Variables & \multicolumn{7}{c}{ Percentage of workforce exposed to } \\
\hline & HL & AP & HF & RW & VT & BJ & SP & PP \\
\hline Occupation & $\mathrm{n}(\%)$ & $\mathrm{n}(\%)$ & $\mathrm{n}(\%)$ & $\mathrm{n}(\%)$ & $\mathrm{n}(\%)$ & $\mathrm{n}(\%)$ & $\mathrm{n}(\%)$ & $\mathrm{n}(\%)$ \\
$\quad$ Electrician & $21(70)$ & $26(87)$ & $21(70)$ & $11(37)$ & $15(50)$ & $3(10)$ & $14(47)$ & $15(50)$ \\
Mechanical & $30(79)$ & $25(66)$ & $22(58)$ & $25(66)$ & $25(66)$ & $6(16)$ & $13(34.2)$ & $25(66)$ \\
Loader driver & $13(54.2)$ & $7(29.2)$ & $6(25)$ & $19(79.2)$ & $5(21)$ & $19(79.2)$ & $15(62.5)$ & $5(21)$ \\
Miner & $21(64)$ & $12(36.4)$ & $12(36.4)$ & $13(39.4)$ & $10(30.3)$ & $10(30.3)$ & $6(18.2)$ & $14(42.4)$ \\
Locomotive drivers & $3(60)$ & $1(20)$ & $1(20)$ & $3(60)$ & $1(20)$ & $3(60)$ & $3(60)$ & $2(40)$ \\
Supervisory & $20(49)$ & $15(37)$ & $11(27)$ & $13(32)$ & $10(24.4)$ & $11(27)$ & $14(34.1)$ & $19(46.3)$ \\
Other & $15(48.3)$ & $14(45.2)$ & $10(32.3)$ & $9(29)$ & $10(32.3)$ & $5(16.1)$ & $10(32.3)$ & $4(13)$ \\
\hline
\end{tabular}

Others: callout clerks, bobcat drivers, draughtsmen, pump chamber and surge bin operators. HL: Heavy lifting, AP: Awkward postures, HF: High Hand Force, RW: Highly repetitive work, VT: Vibration tools, BJ: Bouncing or jarring, SP: Static postures, PP: Pushing and pulling. 
work (93 exposures), while bouncing and jarring had the least number of exposures (57). Table 4 below shows the percentage of the workforce in each occupation exposed to ergonomic risk factors.

The following activities were significantly associated with back injuries: working with the back bent without support was significantly associated with both upper $(p=0.024)$ and lower back $(p=0.020)$ injuries. Significant associations were also found between wrist/hand injuries and grasping an unsupported object(s) weighing $5 \mathrm{~kg}$ or more per hand or grasping with a forceful grip $(p=0.049)$ and grasping objects with the wrist bent $(p=0.016)$. Participants were also asked whether their job involved use of hand tools with high vibration levels. A significant association ( $p=0.022$ ) was found between wrist injury and use of hand tools such as percussive tools (i.e., jack hammers and chipping hammers), impact wrenches and chain saws.

\section{Discussion}

\section{Demographic characteristics}

The response rate of $40.4 \%$ in this study was low compared with the rates reported in other studies ${ }^{4,19,20)}$. With such a low response rate, generalization of the findings to other similar mining populations in Zambia may be difficult. The mean age of the mine workers was 40.31 years, with a standard deviation of 8.57 years. This large standard deviation signifies a big deviation in the age of mine workers, which means that the majority of workers were between 32 and 49 years old. Therefore, the age range and moderate standard deviation compared with the mean indicate that the majority of the Zambian mine workers are in the middle age group (35-45 years). Regarding experience, the mine workers had adequate work experience, as the study revealed that the mean work experience duration was 13.92 years. The demographic findings in this study are in line with findings reported in similar studies ${ }^{3,12,19)}$. Previous studies ${ }^{3,19)}$ reported mean ages of 37.34 and 40 years respectively. These authors also reported mean work experience durations of between 14 and 15 years. Regarding gender, all participants in this study were male, as also reported in similar studies ${ }^{3,12}$.

\section{Identification and description of injury prevalence}

The results of this study revealed a lower prevalence $(42.6 \%)$ of work-related musculoskeletal injuries (WMSIs) amongst mine workers than reported in similar studies ${ }^{6,9,21)}$. The prevalence found in this study was, however, higher than those reported among South African gold, platinum and coal mine work$\mathrm{ers}^{22)}$. The definition of injury and injury prevalence adopted in this study was different from those used in some of the other studies. In this study, injury was defined as injuries of the musculoskeletal system (i.e., muscles, joints, ligaments, tendons and nerves) according to a study ${ }^{22}$ conducted in South Africa, and injury prevalence was calculated from the total of mine workers who had least sustained one or more WMSIs at any time in the past 12 months. These definitions limited the comparability of this study with many similar studies because the other studies defined injury as one, resulting in one or more days lost from work ${ }^{21,23)}$ while prevalence was either defined as injury rate per 100,000 mine workers ${ }^{6,17)}$, number of injuries per 1,000 persons $^{4,24,25)}$ or number of injuries per 100 mine workers ${ }^{21)}$. The raised issues of injury and injury prevalence definitions could not be ruled out due to the nature of this study. It is evident that there is a need to find a common definition that can be used in research for WMSIs that would facilitate the process of monitoring the prevalence of these injuries and evaluating interventions aimed at improving the situation.

\section{Body parts injured}

The results yielded in this study agree with those reported in another study ${ }^{14)}$ that reported the lower back, neck, shoulders and hands as body regions commonly involved in WMSIs. In the present study, injury was most frequently reported in the lower back as was also found in previous studies ${ }^{20,22,26-28)}$. The findings of the present study with regard to injuries of the lower back agree with those of similar studies that found that back injuries represented 32-87\% of the total injuries incurred by underground mine workers $^{3,22,28)}$. Furthermore, contrary to some previous studies ${ }^{22,26-28)}$ that reported that the knee was the most affected joint after the back, the present study found the wrists/hands $(35,40.7 \%)$ to be second most common injury, possibly due to high levels of repetitive bending and twisting of the hands/wrists. The study also found that the ankles/feet were the most affected part of the lower limbs. In addition, the findings indicated that miners presented a higher prevalence of low back injuries than other occupations. This finding is consistent with a study conducted in South Africa ${ }^{22)}$, which found the majority of back injuries among miners (rock drill operators and winch operators) at two South African mines. The study also found miners to have the highest prevalence of wrist/hand injuries among all underground mine occupations, most probably due to variations in sample compositions in terms of job types.

\section{Ergonomic risk factors}

The literature shows that ergonomic risk factors for musculoskeletal injuries in the mines include highly 
repetitive motions, forceful exertions, vibration exposures, poor/awkward posture, forceful gripping and jolting/jarring 9, 14,27). This is specifically evident in the industrially developing nations where manual labor involved in physically demanding tasks is a dominant factor and where manual handling involving lifting of heavy burdens is inherent within the industry despite industrial mechanization ${ }^{3)}$. In the current study, mine workers from different occupations reported risk factors for their job types. The mine workers reported exposures to eight (8) different ergonomic risk factors, namely, heavy lifting, awkward postures, high hand force, highly repetitive work, vibrating tools, bouncing or jarring, static postures and pushing/pulling. The present study found high levels of heavy lifting, awkward postures, forceful gripping, pushing/pulling and highly repetitive work. The least reported exposure was bouncing and jarring. These findings are in part consistent with the findings of a similar study conducted in the United States ${ }^{29}$. However, these authors also reported high levels of bouncing/jarring, which, in the present study, was the least reported. This could be explained by the difference in the job type composition of the samples and variation in the degree of mechanization between the Western and developing countries. Another study ${ }^{29)}$ reported repetition as the most frequent risk factor exposure, followed by heavy lifting and forceful gripping, whereas exposure to vibration was the least reported. In the present study, heavy lifting was the most frequently reported risk factor followed by awkward posture and repetition. It could be assumed that developed countries have better work policies, and hence preventative programs like ergonomics are well implemented. Regarding the relative low levels of heavy lifting exposures in Western countries, the researchers attribute the difference to better mechanization than in developing countries where many workers still lift heavy loads.

Exposure to ergonomic risk factors appeared to be most prevalent for the following body parts: the back, shoulders, neck and hands/wrists. The study found that the majority $(30,79 \%)$ of mechanics reported exposures to heavy lifting. These workers reported lifting unaided an object heavier than $25 \mathrm{~kg}$ (55 lbs) more than 10 times per day. However, not only mechanics, but also other mine workers like electricians $(21,70 \%)$, miners $(21,64 \%)$ and supervisory $(20$, $49 \%$ ) reported high exposures though in relatively low frequencies. A Ghanaian author ${ }^{3)}$ stated that underground engineering involves the lifting of heavy machinery parts. Regarding awkward postures, electricians $(26,87 \%)$ and mechanics $(25,66 \%)$ reported the highest exposures. These engineering occupations involve lifting, fitting and pushing objects for long durations and thus are likely to be more exposed to awkward postures like working with the neck bent, working with hands above the head, working with the back bent and kneeling, than their counterparts. Mechanics and electricians also reported high exposures to high hand force $(22,58 \%$, and $21,70 \%$, respectively). In addition, the present study found significant associations between wrist/hand injuries and grasping an unsupported object weighing $5 \mathrm{~kg}$ or more per hand or grasping with a forceful grip $(p=0.049)$ and grasping objects with the wrist bent $(p=0.016)$. These findings are consistent with those reported in a similar study ${ }^{28}$. These authors further reported that holding hand tools like impact wrenches results in sore hands. The highest frequencies of repetitive work was, as expected, prevalent amongst loader drivers $(19,79.2 \%)$ followed by mechanics $(25,66 \%)$ due to the nature of their jobs. When the use of vibrating tools was considered, mechanics reported the highest exposure $(25,66 \%)$, while electricians reported $(15$, $50 \%$ ) exposures. This could be as a result of the frequent use of tools that typically have high vibration levels like impact wrenches, chain saws and percussive tools like chipping hammers and jack hammers. A significant association $(p=0.022)$ was found between wrist injury and use of hand tools. Miners, supervisors and the others category reported similar exposure frequencies $(10,31 \% ; 10,24.4 \%$ and $10,32.3 \%$, respectively). The loader and locomotive drivers reported the highest exposures to bouncing/jarring (19, $79.2 \%$ and $3,60 \%$, respectively) and static postures (15, $62.5 \%$ and $3,60 \%$, respectively). This could result from poor conditions of roads, loaders and locomotives as reported by many mine workers. Regarding exposure to work involving pushing or pulling against an object, like a trolley, with a maximum effort eight or more times per day, mechanics $(25,66 \%)$ had the most frequent exposures. As indicated earlier, mechanical work involves handling heavy burdens. In addition, a study conducted in South Africa ${ }^{22)}$ found bending and twisting at the waist significantly associated with back injuries. The present study also found working with the back bent without support significantly associated with both upper $(p=0.024)$ and lower back $(p=0.020)$ injuries. The findings of the current study are consistent with other studies ${ }^{20,22,29)}$ indicating that the presence of ergonomic risk factors is associated with development of WMSIs.

\section{Conclusions}

Work-related musculoskeletal injuries are highly prevalent and require urgent intervention. It is envisaged that the identification of ergonomic risk factors associated with WMSIs in this study will assist 
in design of effective prevention programs in the Zambian mining sector. It is likely that the largest number of low-back injuries among miners is influenced by workplace designs necessitating frequent bending and twisting and generally the way work is organized. Despite the conflict in the literature, most researchers agree that the epidemiology linking physical ergonomic exposures at work with risk of WMSIs is methodologically adequate to allow primary prevention.

Acknowledgments: The authors appreciate the support of the Mine Safety Department of the Zambian Ministry of Mines and Minerals Development and the management and participants at Mopani Copper Mines. The authors are also greatly indebted to Mr. Ian Siluyele for his guidance and input with regards to the statistical analysis. Finally, the authors are thankful to Dr. Janet Torma-Krajewski of the National Institute for Occupational Safety and Health (NIOSH), USA for assisting with data collection tools.

\section{References}

1) Joyce S. Major issues in miner health. Environ Health Perspect 1998; 106: 538-43.

2) Kowalski-Trakofler KM, Barrett EA. The concept of degraded images applied to hazard recognition training in mining for reduction of lost-time injuries. $\mathrm{J}$ Safety Res 2003; 34: 515-25.

3) Bio FY, Sadhra S, Jackson C, Burge PS. Low back pain in underground gold miners in Ghana. Ghana Med J 2007; 41: 21-5.

4) Maiti J, Chatterjee S, Bangdiwala SI. Determinants of work injuries in mines-an application of structural equation modeling. Inj Control Safety Promot 2004; 11: 29-37.

5) Lee HY, Yeh WY, Chen CW, Wang JD. Prevalence and psychosocial risk factors of upper extremity musculoskeletal pain in industries of Taiwan: a national wide study. J Occup Health 2005; 47: 311-8.

6) Komljenovic D, Groves WA, Kecojevic VJ. Injuries in U.S. mining operations-a preliminary risk analysis. Safety Science 2007; 46: 792-801.

7) U.S. Bureau of labor statistics. Occupational injury and illnesses in the United States by industry, 1991; 1989: 237.

8) Maiti J. Development of risk indices for underground coal mine workers in India. Mining Technology 2003; 112: 119-24.

9) Karra VK. Analysis of non-fatal and fatal injury rates for mine operators and contractor employees and the influence location. J Safety Res 2005; 36: 413-21.

10) Craig J. Twilight on the Zambian copperbelt? The African diaspora and development. Review of African Political Economy 2002; 29: 364-8.

11) Plessisa SD, Plessis SD. Explanations for Zambia's economic decline. Development Southern Africa 2006; 23: 351-69.
12) Ghosh AK, Bhattacherjee A, Chau N. Relationships of working conditions and characteristics to occupational injuries: a case-control study in coal miners. J Occup Health 2004; 46: 470-8.

13) Safety and Health in Workplace is Critical; Times of Zambia News Paper (2007, August 12).

14) Punnet L, Wegman HD. Work-related musculoskeletal disorders: the epidemiologic evidence and debate. J Electromyogr Kinesiol 2004; 14: 13-23.

15) Bartlett EJ, Kotrlik WJ, Higgins CC. Organizational research: determining appropriate sample size in survey research. Information Technology, Learning and Performing Journal 2001; 19: 43-50.

16) Kuorinka I, Jonsson B, Kilbom A. Nordic questionnaire for the analysis of musculoskeletal symptoms. Applied Ergonomics 1987; 18: 233-7.

17) Komljenovic D, Groves WA, Kecojevic VJ. Injuries in U.S. mining operations-a preliminary risk analysis. Safety Science 2008; 46: 792-801.

18) Patel H, Ekman I, Spertus JA, Wasserman SM, Persson L. Psychometric properties of a Swedish version of the Kansas city cardiomyopathy questionnaire in a chronic heart failure population. Eur $\mathbf{J}$ Cardiovasc Nurs 2008; 7: 214-21.

19) Paul PS, Maiti J. The role of behavioral factors on safety management in underground mines. Safety Science 2007; 45: 449-71.

20) Torma-Krajewski J, Steiner L, Lewis P, Gust P, Johnson K. Implementation of an ergonomics process at a US Surface coal mine. International J Ind Ergon 2007; 37: 157-67.

21) Hull BP, Leigh J, Driscoll TR, Mandryk J. Factors associated with occupational injury severity in the New South Wales underground coal mining industries. Safety Science 1996; 21: 191-204.

22) Dias B, Shutte PC. Work-related musculoskeletal Disorders in the South African mining industry. Occupational Health and Safety 2005.

23) Coleman PJ, Kerkering JC. Measuring mining safety with injury statistics: lost workdays as indicators of risk. J Safety Res 2007; 38: 523-33.

24) Loewenson R. Globalization and occupational health: a perspective from South Africa. Bulletin of the World Health Organization. 2001; 79: 863-8.

25) Paul PS, Maiti J, Dasgupta S, Forjouh SN. An Epidemiological study of injury in mines: Implication for safety promotion. Int J Inj Contr Saf Promot 2005; 12: 157-65.

26) Sari M, Duzgun HSB, Karpuz C, Selcuk AS. Accident analysis of two Turkish underground coal mines. Safety Science 2004; 42: 675-90.

27) Wiehagen WJ, Turin FC. Ergonomic assessment of musculoskeletal risk Factors at four mine sites: underground coal, surface copper, surface phosphate, and underground limestone. Information Circular 2004; 9475.

28) Moore SM, Bauel ER, Steiner LJ. Prevalence and cost of cumulative injuries over two decades of technological advances: a look at underground coal mining in the U.S., 2007.

29) Torma-Krajewski J, Hipes C, Steiner L, BurgessLimerick R. Ergonomic interventions at Vulcan Materials Company. Pittsburgh (PA): National Institute for Occupational Safety and Health (NIOSH); 2007. 